\title{
Effect of layered silicate nanoclay on the properties of silane crosslinked linear low-density polyethylene (LLDPE)
}

\author{
H. Azizi ${ }^{1 *}$, J. Morshedian $^{1}$, M. Barikani ${ }^{1}$, M. H. Wagner $^{2}$ \\ ${ }^{1}$ Iran Polymer and Petrochemical Institute, P.O.Box 14965/115, Tehran, Iran \\ ${ }^{2}$ Polymertechnik/Polymerphysik, TU-Berlin, Fasanenstr. 90 D, 10623, Berlin, Germany
}

Received 23 December 2009; accepted in revised form 17 February 2010

\begin{abstract}
In the present work, the effect of pristine layered silicate montmorillonite (MMT) nanoclay on the properties of silane-crosslinked LLDPE prepared by melt compounding is investigated. The effect of the sequence of feeding additives (nanoclay and grafting agent) into the mixer on gel content, thermal and mechanical properties were studied. Results demonstrate that the sequence of feeding additives influences the final properties of nanocomposites. For samples prepared by first grafting of silane on LLDPE followed by incorporation of nanoclay into the polymer matrix, the gel content and the rate of crosslinking increased, while the elongation at break decreased. For samples prepared by first mixing nanoclay into the LLDPE matrix followed by the grafting reaction, the rate of crosslinking and the tensile properties did not change significantly. The gel content increased with increasing content of nanoclay for both process routes due to an enhanced permeation of water molecules into the polymer matrix in the presence of polar montmorillonite particles. Wide angle X-ray scattering (WAXS) results proved the intercalation/partial exfoliation morphology of nanoclay in the silane-grafted LLDPE matrix. Differential scanning calorimetry (DSC) data showed multiple melting behaviour for crosslinked samples which is indicative for different crystalline structures of the sol and gel part of the LLDPE matrix.
\end{abstract}

Keywords: nanocomposites, LLDPE, silane crosslinking, layered silicate, gel content

\section{Introduction}

Linear low-density polyethylene (LLDPE) is a versatile material for application in cable and film manufacturing industries. The silane crosslinking process converts the virgin polyethylene to a new material with improved upper service temperature, chemical and environmental stress cracking resistance (ESCR) and electrical properties [1-3]. Crosslinked linear low-density polyethylene (XLLDPE) is used for low-to-medium voltage power cable insulation and heat shrinkable films. The use of mineral fillers to adjust the properties of silane - crosslinked polyethylene is well established. Metal hydroxides such as magnesium hydroxide and aluminium tri-hydrate are usually used to improve the flame retardancy of crosslinked polyethylene. Calcium carbonate is also used to adjust price and elastic modulus. However, to achieve desirable properties, a high loading of mineral fillers should be used which may lead to a dramatic decrease in mechanical properties and an increase of the density of the final product [4-9]. Also, the effect of aluminium hydroxide, antimony trioxide and EVA on the properties of silane crosslinked LDPE was investigated [10].

It has been reported that using layered silicates with large aspect ratios (a few nanometer thick but hundreds to thousands of nanometers long) in a polymer matrix improves mechanical properties [1113], reduces thermal expansion coefficient [14], gas permeability [15] and flammability $[16,17]$ of the polymer. These improvements can be achieved 
by using small amounts of nanofiller $(\leq 5 \%)$ compared to $\sim 40 \%$ for micro-fillers. The main problem in the preparation of $\mathrm{PE} /$ layered silicate nanocomposites is the difference in the polarity of nonpolar polyethylene versus polar filler leading to weak interfacial adhesion between polymer matrix and nanofiller. Several strategies have been followed to improve the intercalation of polyethylene into the layers of nanoclay including in situ polymerization of polymer in the presence of nanoclay, modification of nanoclay with non-polar groups [18, 19], solvent blending [20], and using compatibilizers (usually maleated PE or PP), which is the most common method in the melt compounding process of nanocomposites [21-26].

According to the studies reported in the literature about modification of layered silicates with alkoxy silane [27-30] it can be expected that using layered silicates in silane grafted polyethylene leads to improved intercalation and exfoliation of nanofiller in the presence of polar silane-grafted polyethylene. Moreover, the flammability and barrier properties can be improved which are two important parameters in the film and packaging industries. The main target of this work is to present the results of the effect of nanoclay on the gel content of silane-grafted and moisture crosslinked polyethylene. The effect of adding nanoclay before or after silane-grafting of LLDPE was investigated. Morphological studies were performed to interpret the changes in mechanical and network properties resulting from the addition of nanoclay.

\section{Experimental}

\subsection{Materials}

The polymer matrix used in this study was a linear low-density polyethylene with trade name LL209AA from Arak Petrochemical Co. (Iran), with melt flow index (MFI) of $0.9 \mathrm{~g} / 10 \mathrm{~min}$ and density $=0.920 \mathrm{~g} / \mathrm{cm}^{3}$.

The nanofiller was layered silicate (Cloisite $\mathrm{Na}^{+}$) from Southern Clay Products Inc., USA. It is a natural montmorillonite (MMT) without any modification, density $=2.86 \mathrm{~g} / \mathrm{cm}^{3}$ and $d$-spacing $\left(d_{001}\right)=$ $11.7 \mathrm{~A}^{\circ}$. This grade was chosen because of its higher hydrophilicity compared to other commercial grades.

The grafting additive was Siflin 13 which is a mixture of $92.5 \mathrm{wt} \%$ vinyl-tri-methoxysilane (VTMOS) and $7.5 \mathrm{wt} \%$ di-cumyl-peroxide (DCP) from Evonik, Germany in liquid form.

\subsection{Processing}

An internal mixer from Brabender, Germany (model WHT 55), with roller type rotors and mixer capacity of $55 \mathrm{~cm}^{3}$ was used for preparation nanocomposites and silane-grafted samples. A fill factor of 0.75 was selected based on the density of the compounds. The amount of silane/DCP content was kept constant at $1.8 \mathrm{phr}$ (parts per hundred parts of polyethylene) which means $1.665 \mathrm{phr}$ VTMOS and $0.135 \mathrm{phr}$ DCP. Three levels of MMT were used: 1, 2 and 3 phr. One sample of silane-grafted polyethylene without nanoclay was also prepared. Two different methods were used for preparation silanegrafted LLDPE/MMT nanocomposites based on the sequence of feeding additives into the mixer as follows:

1) First addition of nanoclay into the mix, followed by incorporation of the grafting additives to produce silane-grafted polyethylene. We designate the data obtained by this process as 'Beforegrafting (BG)'. For this process, the nanoclay was added at 2 min of mixing, and Siflin 13 was added at 3 min of mixing. The total mixing time was $12 \mathrm{~min}$.

2) First addition of grafting agents into the mix, followed by incorporation of nanoclay. We name this process as 'After-grafting (AG)'. For this process the grafting agents were added at $2 \mathrm{~min}$, and the nanoclay was added at $8 \mathrm{~min}$ of mixing. The total mixing time was $17 \mathrm{~min}$.

The screw rotation speed was constant at $60 \mathrm{rpm}$ for all experiments. The temperature was fixed at $125^{\circ} \mathrm{C}$ for $3 \mathrm{~min}$, and then increased to $190^{\circ} \mathrm{C}$ with a rate of $32^{\circ} \mathrm{C} / \mathrm{min}$. The mixing was continued for different periods of time based on the processes selected. For both processes, at first polyethylene was fed to the mixer and was molten. After melting of the polymer, nanoclay and/or grafting agents were added. We choose approximately similar mixing times for the nanoclay, resulting therefore in different total mixing times of the two processes. For all experiments the variation of torque of the internal mixer with time was monitored during the mixing/grafting process.

Samples from internal mixer were compression moulded in a laboratory press (Toyoseiki, Japan) at 
$200^{\circ} \mathrm{C} / 25 \mathrm{MPa}$ to form sheets and films. The films were used for FTIR characterization, and the sheets with $1 \mathrm{~mm}$ thickness were used for investigation of mechanical properties and for morphological studies.

\subsection{Crosslinking}

Crosslinking of silane grafted samples was performed in hot water at $90^{\circ} \mathrm{C}$. The total time of crosslinking was 24 hours. The sheets prepared by compression moulding were put in a hot water bath. At different periods of time (1, 3, 5 and $24 \mathrm{~h})$, a piece was cut from the sheets for determination of gel content.

\subsection{Analyses}

Fourier transfer infrared spectroscopy (FTIR) was used to follow the formation of new chemical groups upon silane grafting and MMT addition. The films were washed by excess acetone before FTIR scans to remove unreacted silane. In this study the FTIR spectra were recorded by a PerkinElmer 2000X collecting 25 scans and using a resolution of $4 \mathrm{~cm}^{-1}$.

Tensile properties were measured according to ASTM D 638 with a tension rate of $25 \mathrm{~mm} / \mathrm{min}$ at room temperature. Dumbbell-shaped specimen for measurement of tensile properties were punched from crosslinked sheets.

The gel content of samples was measured according to ASTM D 2765 by extraction of the samples in p-xylene for $16 \mathrm{~h}$. Small angle X-ray scattering (WAXS) was used to study the morphology of the nanocomposites and of the virgin clay. The X-ray beam was $\mathrm{Co}-\mathrm{Ka}(\lambda=0.17889 \mathrm{~nm})$ radiation. The scanning rate was $0.05 \%$, and the scattering angle 2-theta ranged from 4 to $10^{\circ}$.

Melting and crystallization behaviour were studied by a differential scanning calorimeter, model 8220 from Mettler Toledo, Germany. The heating program was as follows:

- First heating scan: Heating from 40 to $200^{\circ} \mathrm{C}$ with a rate of $10^{\circ} \mathrm{C} / \mathrm{min}$.

- Keeping the sample at $200^{\circ} \mathrm{C}$ for 5 min to erase the thermal history.

- First cooling scan: Cooling to $40^{\circ} \mathrm{C}$ with a rate of $10^{\circ} \mathrm{C} / \mathrm{min}$.
- Second heating scan: Heating from 40 to $200^{\circ} \mathrm{C}$ with a rate of $10^{\circ} \mathrm{C} / \mathrm{min}$.

The melting and crystallization peaks were obtained from the second heating and first cooling scans, respectively. Percent of crystallinity was calculated from the area of melting $\left(\Delta H_{m}\right)$ by using $293 \mathrm{~J} / \mathrm{g}$ for heat of fusion of $100 \%$ crystalline polyethylene [31] according to the Equation (1):

percentage of crystallinity $=\frac{\Delta H_{m}}{293} \cdot 100$

\section{Results and discussion}

\subsection{Mixing/grafting evaluation}

The variation of torque as a function of mixing time for samples containing different nanoclay concentrations and prepared by the two different process routes is shown in Figures 1 and 2. The first peaks in the figures correspond to the melting of polyethylene. The second peaks are related to the grafting of silane onto the polyethylene. A small increase in torque was observed with the incorporation of nan-

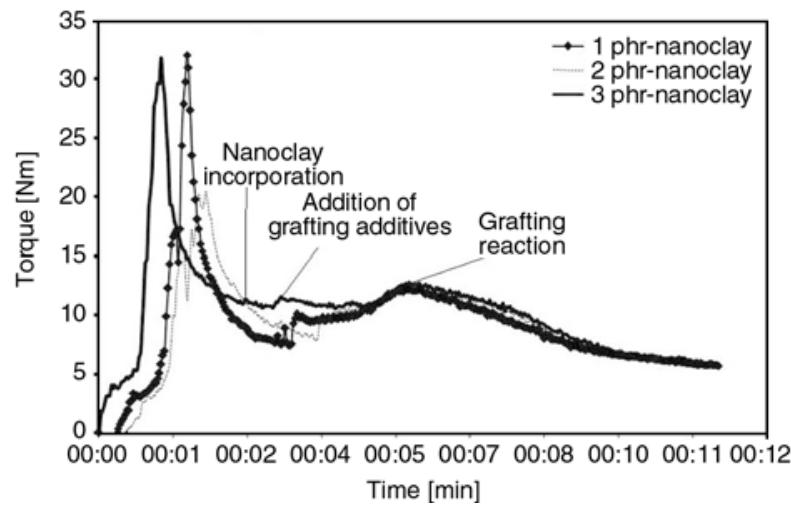

Figure 1. Variation of internal mixer torque with time for different samples prepared by BG process

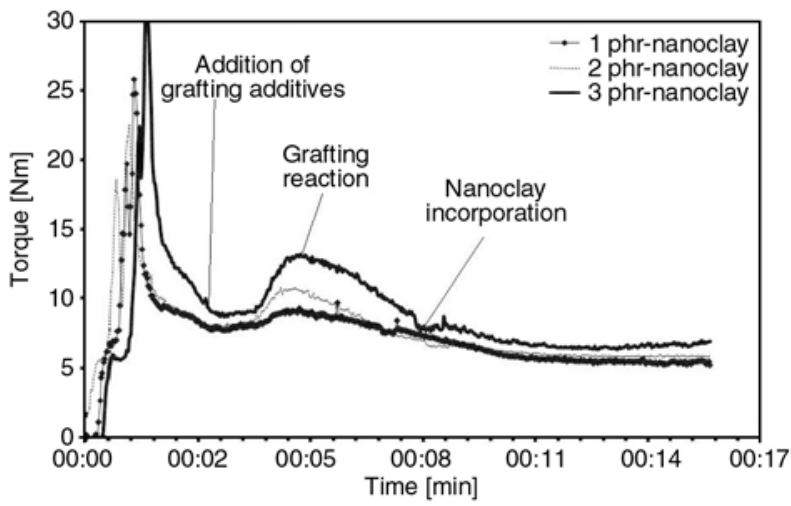

Figure 2. Variation of internal mixer torque with time for different samples prepared by AG process 
oclay at $3 \mathrm{~min}$ for the $\mathrm{BG}$ process, and at $8 \mathrm{~min}$ for the AG process. The peak for grafting confirms that the grafting reaction has successfully taken place.

\subsection{FTIR analysis}

Figure 3 shows FTIR spectra for virgin LLDPE and pure montmorillonite. For pure MMT, four peaks at $521 \mathrm{~cm}^{-1}$ (Si-O bending), $1010 \mathrm{~cm}^{-1}$ ( $\mathrm{Si}-\mathrm{O}$ stretching, in-plane), $1650 \mathrm{~cm}^{-1}$ (-OH bending, hydration) and $3635 \mathrm{~cm}^{-1}$ (-OH stretching or Al-Al-OH stretching) were observed. The FTIR spectra of silane grafted LLDPE and corresponding nanocomposites with $3 \mathrm{phr}$ MMT obtained from the two different processes are shown in Figure 4. The main differences between nanocomposites and virgin silane-grafted LLDPE are the appearance of new peaks at 1033, 362 and $514 \mathrm{~cm}^{-1}$. The new absorbance peaks lead to broadening the peaks of 1090 and $3600 \mathrm{~cm}^{-1}$ of the virgin silane-grafted sample. The peak at $1033 \mathrm{~cm}^{-1}$ is due to $\mathrm{Si}-\mathrm{O}-\mathrm{Si}$ stretching vibrations, and the peak at $3620 \mathrm{~cm}^{-1}$

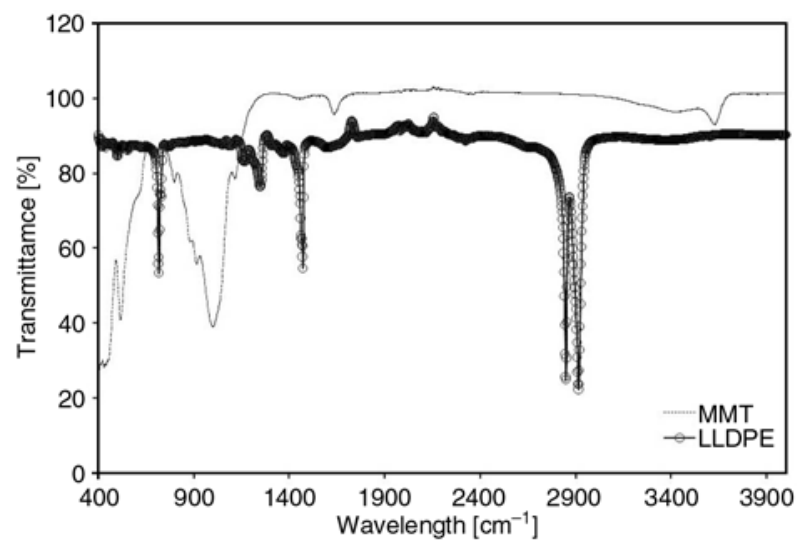

Figure 3. FTIR spectra of virgin LLDPE and pure monmorillonite (MMT)

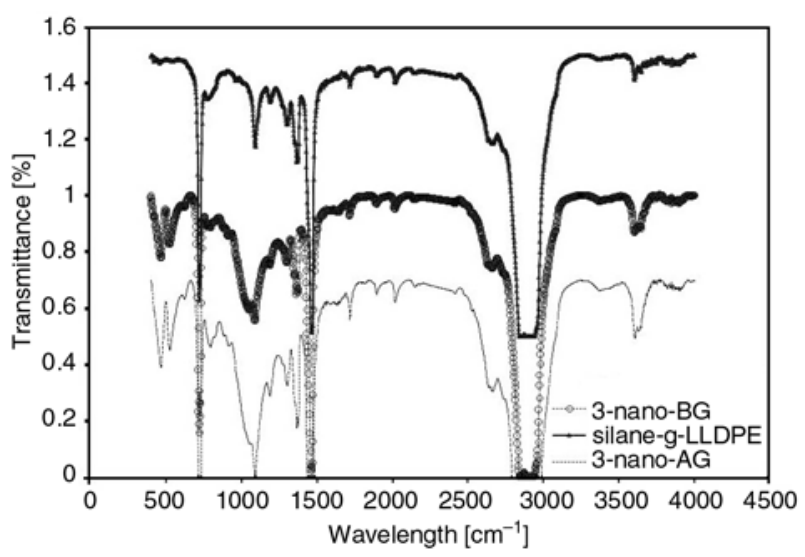

Figure 4. FTIR spectra of silane grafted LLDPE and its nanocomposites with $3 \mathrm{phr}$ nanoclay prepared by different methods corresponds to $\mathrm{Al}-\mathrm{Al}-\mathrm{OH}$ stretching. However, it should be noted that some of the peaks in silanegrafted polyethylene/MMT nanocomposites are overlapping with the peaks of virgin silane-grafted polyethylene because of some similar groups such as $\mathrm{Si}-\mathrm{OCH}_{3}$. The characteristic peaks for $\mathrm{Si}-\mathrm{O}-\mathrm{C}$ groups appear at 1090, 1182 and $817 \mathrm{~cm}^{-1}$. A small peak at $1620 \mathrm{~cm}^{-1}$ due to bending vibration of $-\mathrm{OH}$ groups can be seen for the nanocomposites. The peak at $514 \mathrm{~cm}^{-1}$ is due to bending vibration of $\mathrm{Si}-\mathrm{O}$ groups in MMT. A possible reaction is the formation of chemical bond between nanoclay and grafted polyethylene chains via hydrolysis of methoxy groups to form silanol groups, and consequently the reaction of silanol groups of silanegrafted polyethylene with $-\mathrm{OH}$ groups in the nanoclay by a condensation reaction, which leads to the formation PE-Si-O-Si-MMT. The characteristic peak for $\mathrm{Si}-\mathrm{O}-\mathrm{Si}$ stretching vibration appears at $1033 \mathrm{~cm}^{-1}$. This reaction is possible because of the presence of water in nanoclay. In general, the FTIR spectra confirm the grafting reaction, and presence of nanoclay in the polyethylene matrix.

\subsection{WAXS analysis}

Figure 5 shows the diffraction patterns of virgin nanoclay (MMT) and of different silane-grafted LLDPE/MMT nanocomposites prepared by the two different methods. The WAXS patterns indicate the intercalation/partially exfoliation of the MMT in the LLDPE matrix. A shift of the characteristic diffraction peak to lower $2 \theta$-angles indicates the increasing $d$-spacing between silicate layers in

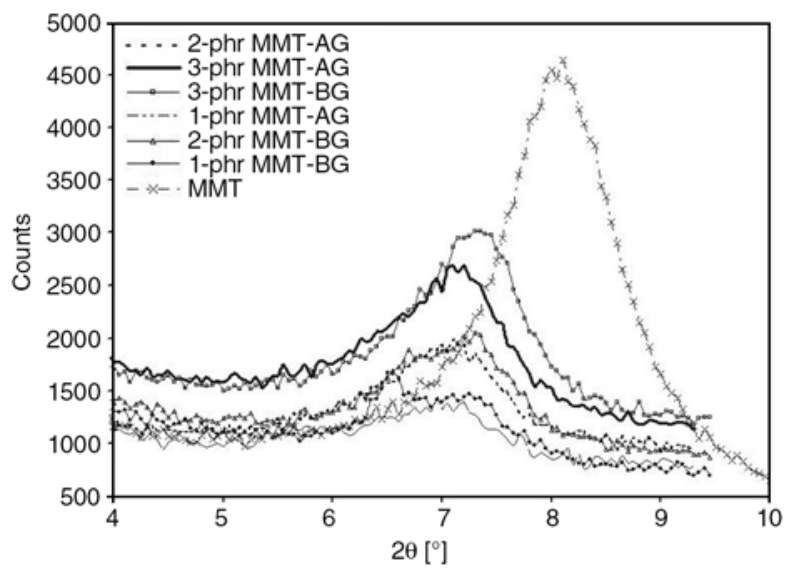

Figure 5. XRD spectra of virgin MMT powders and silane-grafted LLDPE/MMT nanocomposites prepared by $\mathrm{AG}$ process and $\mathrm{BG}$ process 
MMT, which is referred to as intercalation. The broadening of the characteristic peak is suggested to be the result of partial exfoliation [32]. Disappearance of the peak would indicate full exfoliation, which was not observed for our samples with a constant amount of grafting agents. It seems that for samples containing 1 and $2 \mathrm{phr}$ of nanoclay, partial exfoliation is easier achieved than for samples containing $3 \mathrm{phr}$ nanoclay. On the other hand, samples prepared by the AG process showed enhanced intercalation compared to samples prepared by the BG process. However, it seems that the best intercalation was achieved for the sample containing $1 \mathrm{phr}$ nanoclay prepared by the BG process, since for this sample, the shift of the $2 \theta$-angle to lower scattering angles is more pronounced than for all other samples (from 8.1 to $\left.6.5^{\circ}\right)$.

\subsection{Effect of nanoclay on gel content}

Gel content is an important parameter in crosslinked polyethylene because many properties of the material will be affected by this parameter. For wire and cable insulation, which should pass the hot-set test, gel content is the most important parameter. For the silane crosslinking technology, the rate of crosslinking is an issue for crosslinking of thick shapes. Silane crosslinking needs more time than other crosslinking methods such as peroxide crosslinking and irradiation crosslinking. This drawback limits the application of the silane crosslinking technology to thin products. In industry, often catalysts are used to increase the rate of crosslinking. However, catalysts based on a tin compound (di-butyl-tin-dilaurate) are environmentally harmful and expensive. Figures 6 and 7 show the variation of gel content for samples with different content of nanoclay as obtained by the two process routes. Parameter is the crosslinking time. For the BG process, the gel content does not change significantly with nanoclay loading. However, the gel content for the sample containing $1 \mathrm{phr}$ nanoclay was somewhat higher than for the other samples. This may be attributed to a better dispersion (partial exfoliation of nanoparticles as seen from WAXS) of this sample. The better dispersion of nanoclay results in a more uniform distribution of water molecules in the samples, which leads to higher gel content.

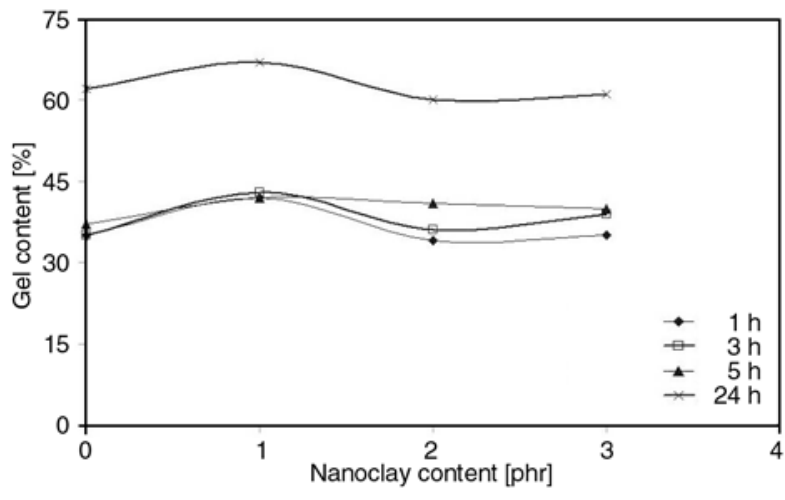

Figure 6. Change of gel content with nanoclay concentration for samples obtained from BG process

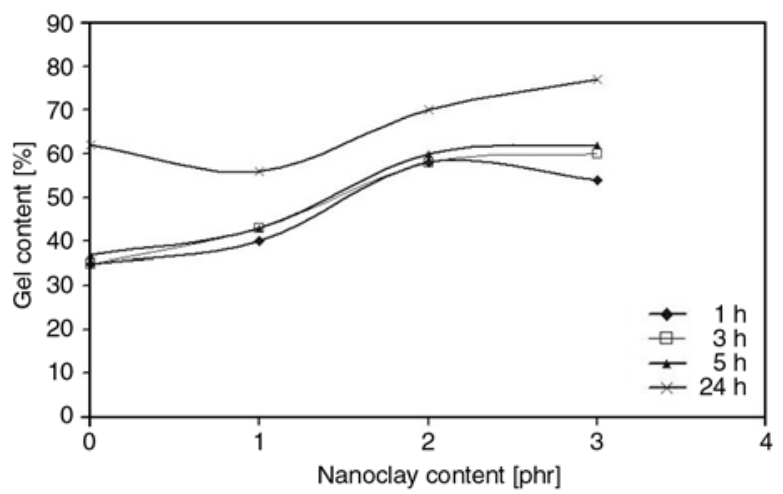

Figure 7. Change of gel content with nanoclay concentration for samples obtained from AG process

For samples prepared by AG process, in which nanoclay was added after the silane grafting reaction, a different behaviour is observed. For these samples, the gel content increases with the increase of the nanoclay content. The lower gel content observed in samples prepared by the BG process in comparison to samples produced by the AG process seems to be due to the absorption of silane molecules by the nanoclay before grafting to the polyethylene chains. A reaction of silane molecules with the nanoclay due to $-\mathrm{OH}$ groups in the nanoclay structure is very likely. The variations of the gel content for different MMT concentrations as a function of the crosslinking time are shown in Figures 8 and 9 for the two process routes. It is clear from Figure 9 that incorporation of pristine nanoclay even at low amounts increases significantly the rate of crosslinking. The rate of crosslinking increases with increase of nanoclay loading, with the increase of the rate of crosslinking being more pronounced for samples containing 2 and $3 \mathrm{phr}$ of nanoclay. For samples prepared via BG process, no significant change in the rate of crosslinking was observed except for the sample with $1 \mathrm{phr}$ of nanoclay, which showed a 


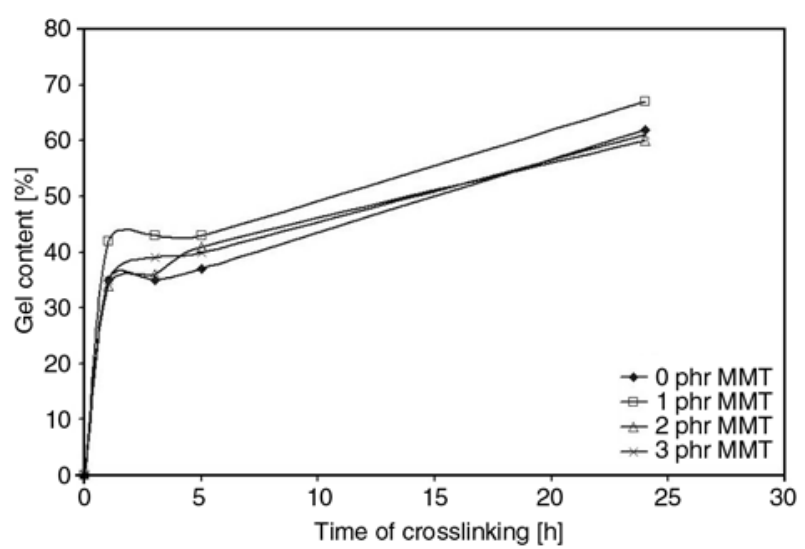

Figure 8. Variation of gel content with time of crosslinking for samples prepared by BG process

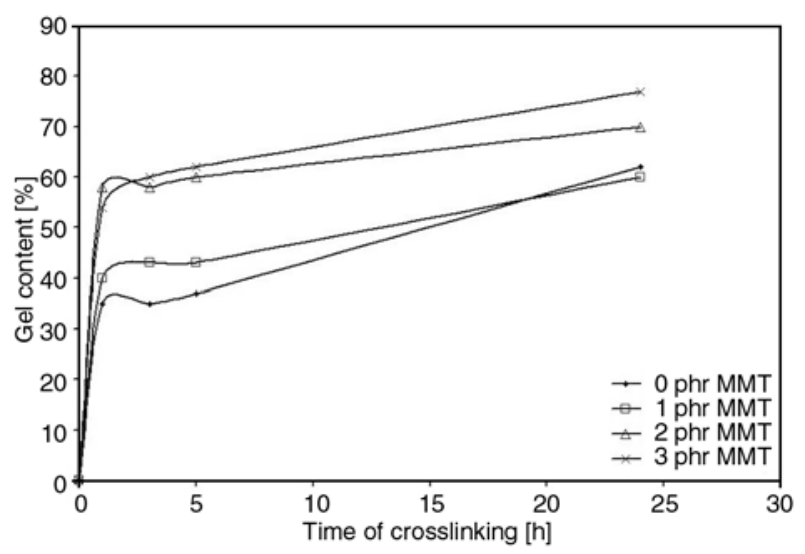

Figure 9. Variation of gel content with time of crosslinking for samples prepared by AG process

Table 1. The ratio [\%] between gel contents at 3 and $24 \mathrm{hrs}$ for different samples prepared by different process routes

\begin{tabular}{|l|c|c|c|c|}
\hline \multicolumn{1}{|c|}{ MMT content } & 0 & 1 phr & 2 phr & 3 phr \\
\hline Before grafting [\%] & 56 & 64 & 60 & 64 \\
\hline After grafting [\%] & 56 & 72 & 83 & 80 \\
\hline
\end{tabular}

small increase in the rate of crosslinking. The percentage of gel content achieved after 3 hours of crosslinking (i.e. the ratio between the gel content at 3 hours and at 24 hours of crosslinking) are listed in Table 1 for the different samples. For the BG process, the maximum percentage of final gel content was obtained for samples containing 1 and $3 \mathrm{phr}$ of nanoclay with $64 \%$ compared to $56 \%$ for the sample without nanoclay. For the AG process, the percentage of maximum gel content was increased to $72 \%$ for the sample with $1 \mathrm{phr}$ nanoclay, and to 83 and $80 \%$ for samples containing 2 and 3 phr nanoclay, respectively.

It is well-known that in silane-crosslinked polyethylene, crosslinking takes place first by hydrolysis of methoxy groups $\left(-\mathrm{OCH}_{3}\right)$ to form silanol groups
$(\mathrm{Si}-\mathrm{OH})$. Then via a condensation reaction, the silanol groups will change to siloxane $(\mathrm{Si}-\mathrm{O}-\mathrm{Si})$ bonds between the polyethylene chains. Therefore, the availability of water is a key parameter in silane crosslinking of polyethylene. The permeation of water molecules into the polymer backbone is a low-speed and time-consuming process. Pristine clay is filler with a higher polarity and hydrophilicity compared to other commercial organically modified montmorillonites (OMMT), because of the presence of $\mathrm{Na}^{+}$cations and $-\mathrm{OH}$ groups in its structure. Modification of MMT is usually done by ion exchange reactions using ammonium salts. Therefore it can be concluded that the addition of pristine nanoclay increases the absorption of water molecules by the polymer matrix leading to an increase of the crosslinking rate. The well-dispersed nanoclay leads to a uniform distribution of water molecules in polyethylene. However, it should be kept in mind that nanoclay could in principle also have a detrimental effect on the permeation of water molecules into the polymer matrix due to the barrier properties of nanoclay, which restrict gas and water permeation. The competition between these two effects (enhanced water absorption versus barrier properties) determines the rate of crosslinking. In the case of our study, it seems that water absorption of nanoclay is more important than its potential barrier properties. However, it should be noted that our samples were crosslinked in a hot water bath which guaranteed that enough water molecules were available for crosslinking.

\subsection{Mechanical properties}

Tensile tests were performed to investigate the effect of nanoclay loading on mechanical properties of silane-crosslinked LLDPE. Figures 10 and 11 illustrate the variation of tensile strength (stress at break) and elongation at break, respectively, as a function of nanoclay content for crosslinked samples. The data obtained for the two mixing methods, AG and BG, are presented. Different trends of variation are observed for the samples depending on the process route. For the BG process, tensile strength increased slightly with increasing MMT concentration, while for the AG process, tensile strength shows a tendency to decrease with nanofiller concentration. However, it should be noted that all the samples showed higher tensile strength 


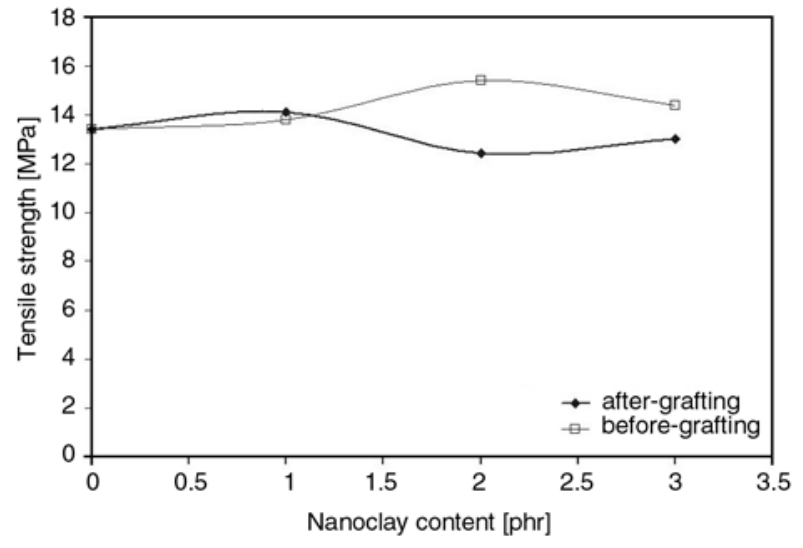

Figure 10. The effect of nanoclay content on tensile strength for samples prepared by different processes

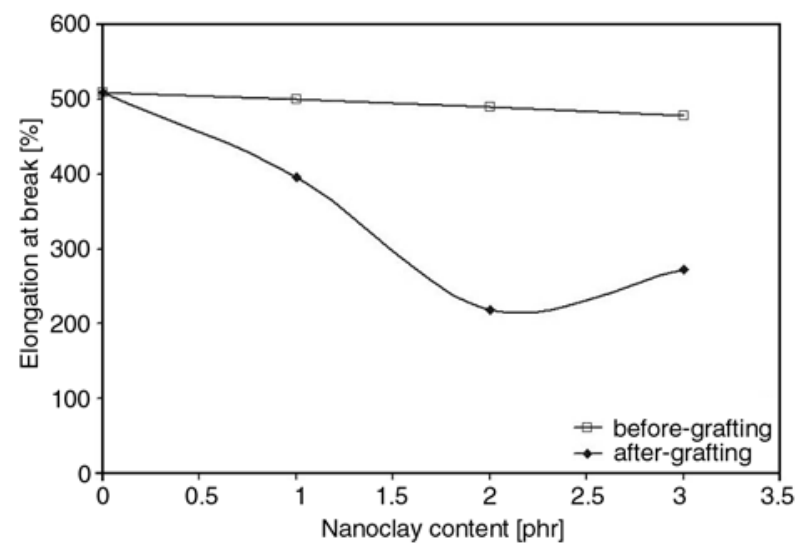

Figure 11. The effect of nanoclay content on elongation for samples prepared by different processes

Table 2. Change in tensile strength [\%] of silane grafted LLDPE with nanoclay concentration

\begin{tabular}{|l|c|c|c|}
\hline \multicolumn{1}{|c|}{ MMT content } & $\mathbf{1} \mathbf{~ p h r}$ & $\mathbf{2} \mathbf{~ p h r}$ & $\mathbf{3} \mathbf{~ p h r}$ \\
\hline Before-grafting [\%] & 3.0 & 15.0 & 7.5 \\
\hline After-grafting [\%] & 5.2 & -7.5 & -3.0 \\
\hline
\end{tabular}

than virgin uncrosslinked LLDPE. According to the manufacturer's data sheet, the tensile strength for virgin LLDPE is $11 \mathrm{MPa}$, and elongation at break is $620 \%$. After crosslinking, the tensile strength increases due to the formation of strong chemical bonds between polymer chains. Table 2 summarizes the change of tensile strength of samples prepared by the two different mixing methods relative to virgin silane-crosslinked polyethylene. The maximum improvement was obtained by the sample with 2 phr nanoclay prepared by BG method with a $15 \%$ increase in tensile strength. The maximum relative reduction in tensile strength was observed for the sample containing $2 \mathrm{phr}$ MMT prepared by the AG method. In general, it can be concluded that the tensile strength of silane grafted LLDPE shows
Table 3. Change in elongation [\%] at break of silane grafted LLDPE with nanoclay concentration

\begin{tabular}{|l|c|c|c|}
\hline \multicolumn{1}{|c|}{ MMT content } & 1 phr & 2 phr & 3 phr \\
\hline Before grafting [\%] & -1.7 & -3.7 & -6.0 \\
\hline After grafting [\%] & -22.0 & -57.0 & -46.0 \\
\hline
\end{tabular}

only small changes as a function of nanoclay content. Although for virgin PE/nanocomposites it has been reported that tensile strength increases with filler content $[33,34]$, in our study with silanecrosslinked polyethylene no significant change in tensile strength at MMT loading up to $3 \mathrm{phr}$ was observed.

The variation of elongation at break versus MMT content is shown in Figure 11. For samples obtained by the BG process, elongation at break did not change considerably with filler content, although a slight decrease is observed. However, for samples obtained through the AG process, elongation at break decreased dramatically with nanoclay concentration. Table 3 summarizes the changes in elongation at break of samples prepared by the two different production methods relative to virgin silane-crosslinked polyethylene. The relative reduction of elongation at break was higher for samples prepared by the AG method and varied between 22 to $57 \%$. The maximum reduction is observed for the sample with $2 \mathrm{phr}$ nanoclay. One reason for such a decrease is the higher gel content of samples prepared by the AG process compared to samples prepared by the BG process. The crosslinks between polymer chains prevent the slippage of polymer chains past one another leading to a decrease in the elongation at break. Another reason may be the firmer integration of nanoclay particles by the AG process into the polymer matrix resulting in higher gel content, a denser network and more interfacial adhesion. This firmer integration affects both the tensile strength and the elongation at break of the samples.

\subsection{Thermal properties}

Figure 12 shows melting thermograms obtained from the first heating scan for different samples prepared by the two different mixing routes. As can be seen crosslinking changes the shape of melting peaks significantly. Multiple melting peaks are observed for crosslinked samples (with and without nanoclay addition) compared to the uncrosslinked 

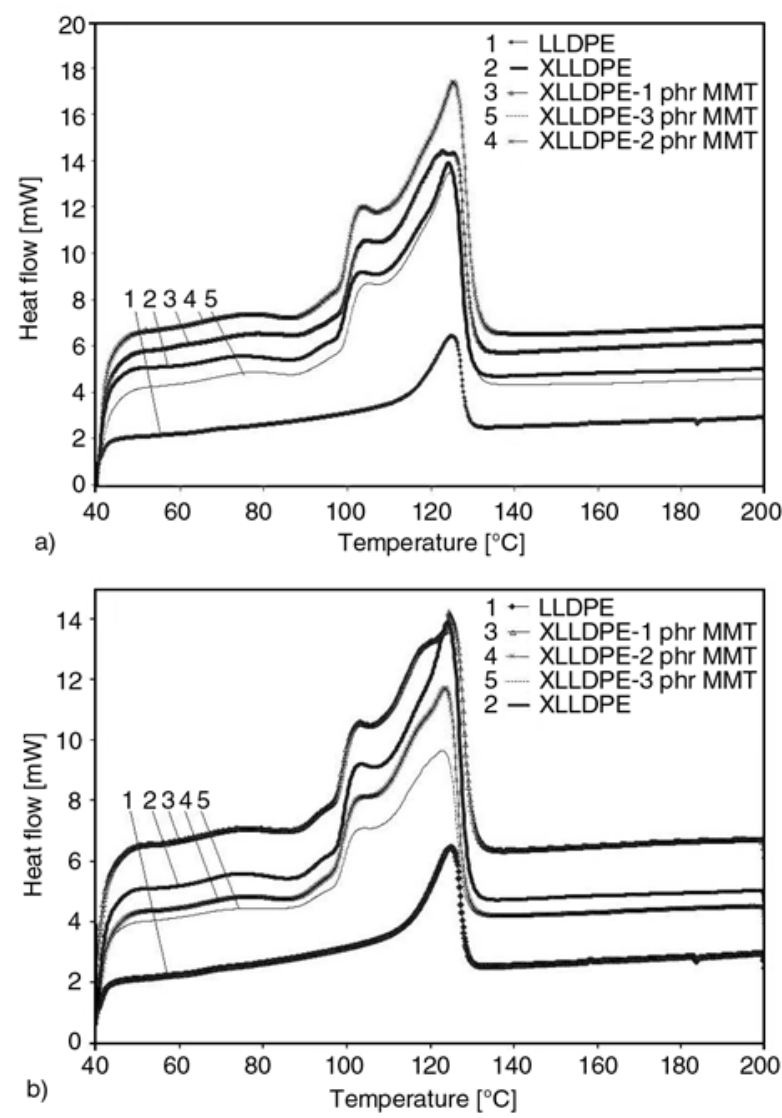

Figure 12. DSC thermograms of first heating scan for different samples prepared by a) BG process and b) AG process

polyethylene. For crosslinked samples, two melting peaks at about 103 and $124^{\circ} \mathrm{C}$ are observed. An endothermic shoulder is also seen at about $89^{\circ} \mathrm{C}$ for crosslinked samples. This type of melting behaviour reveals the molecular heterogeneity in the structure of crosslinked polyethylene. The two melting peaks may be attributed to the melting of two different components in the crosslinked polyethylene: the gel part and the sol part. The higher melting temperature corresponds to the sol part and is close to the melting temperature of uncrosslinked LLDPE $\left(125^{\circ} \mathrm{C}\right)$. The lower melting temperature is related to gel part. The endothermic shoulder at $89^{\circ} \mathrm{C}$ may perhaps be attributed to the formation of newly formed $\mathrm{Si}-\mathrm{O}-\mathrm{Si}$ crystallites as studied by Kuan et al. [35]. Incorporation of MMT did not change the melting behaviour considerably indicating that the nanoclay has not acted as nucleating agent in this study.

The results for second heating scan are presented in Figure 13, and a different behaviour is observed. Here, no multiple melting peaks can be observed. The second peak at $103^{\circ} \mathrm{C}$ has disappeared, and
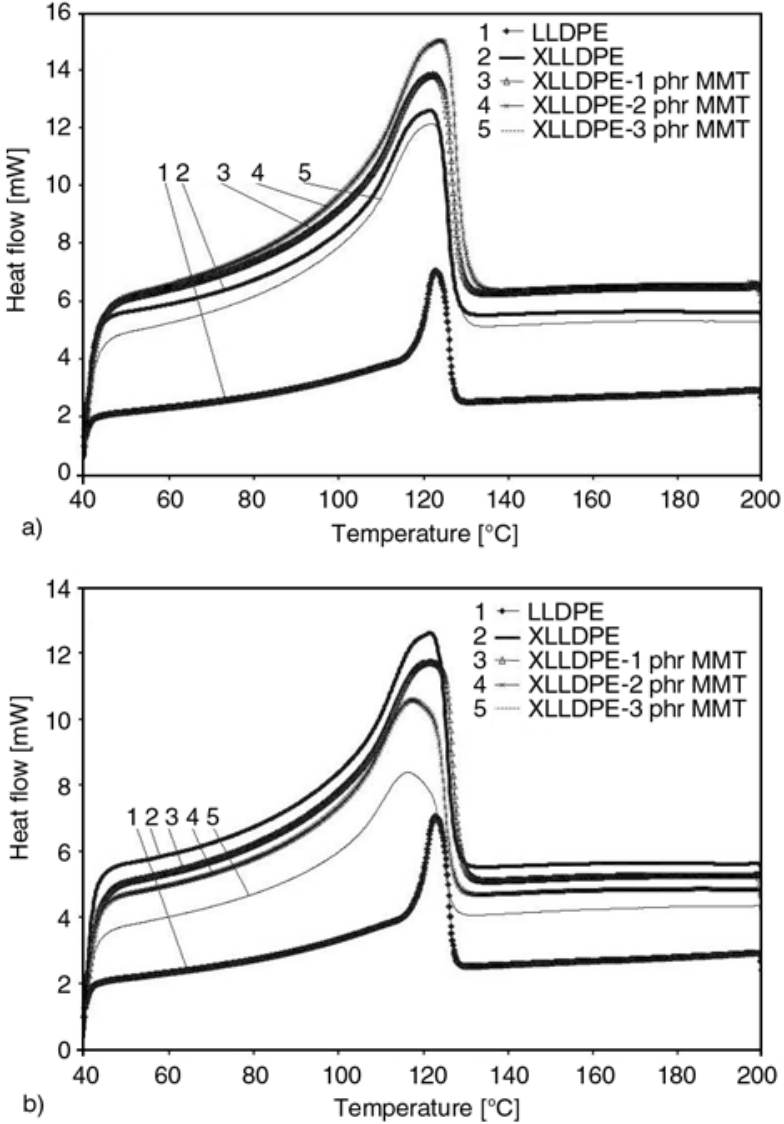

Figure 13. DSC thermograms of second heating scan for different samples prepared by A) BG process and $\mathrm{B}) \mathrm{AG}$ process

instead a broad shoulder leading up to the melting peak at $124^{\circ} \mathrm{C}$ is observed. This may be due to an improved co-crystallization of the sol and gel part of the crosslinked polyethylene after heat treatment to $200^{\circ} \mathrm{C}$.

Figure 14 illustrates the crystallization peaks for samples prepared by the different mixing methods. Similar to the melting behaviour at the first heating run, two different crystallization peaks are observed at temperatures of about $107^{\circ} \mathrm{C}$ (corresponded to crystallization of virgin LLDPE) and $98^{\circ} \mathrm{C}$. For samples prepared by the AG process, with increasing nanoclay content the peak at $98^{\circ} \mathrm{C}$ becomes stronger than that the peak at $107^{\circ} \mathrm{C}$, which weakens considerably. However, for samples prepared by the $\mathrm{BG}$ process, this is not the case. Tables 4 and 5 summarize the data obtained from DSC thermograms, and they include melting temperature $\left(T_{m}\right)$ (from $2^{\text {nd }}$ heating scan), crystallization temperature $\left(T_{c}\right)$ for the strongest crystallisation peak, as well as percentage of crystallinity. For samples obtained by the BG process, the melting point did not change significantly with filler 

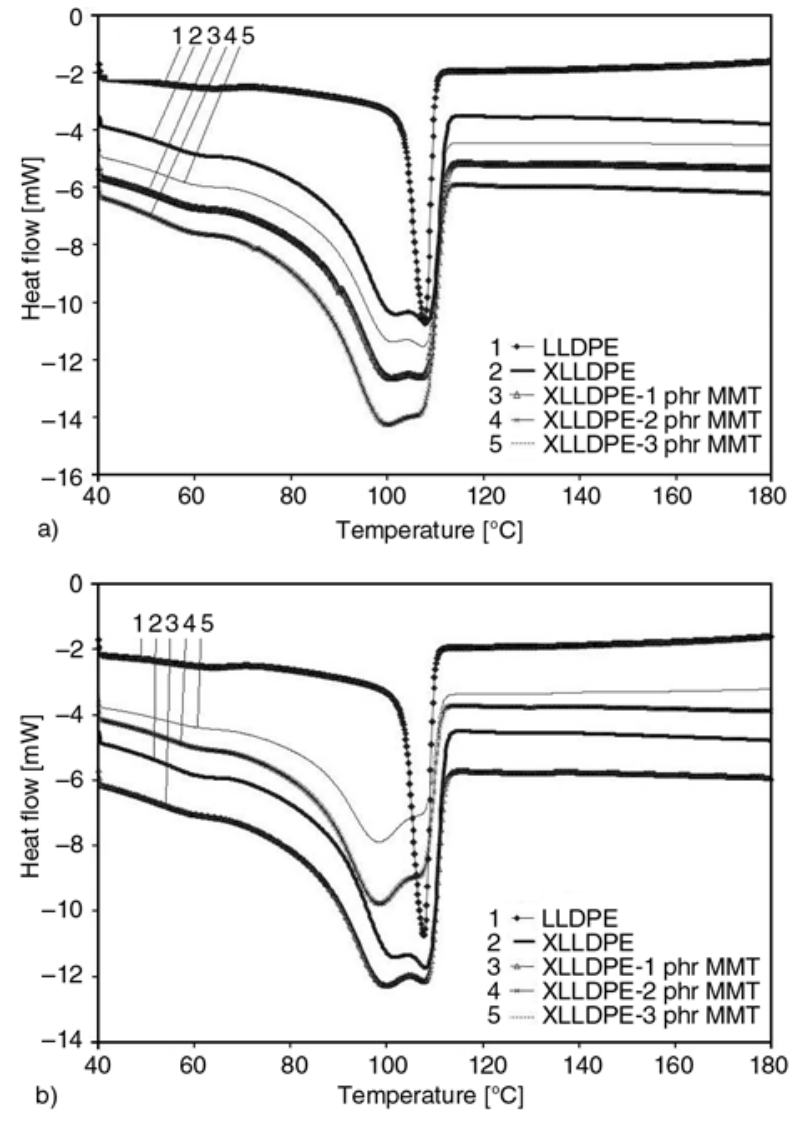

Figure 14. Crystallization peaks for different samples prepared by A) BG process and B) AG process

crosslinking and MMT content. However, for samples obtained by the AG process, the melting point shifted to lower temperatures with increasing nanoclay content. The decrease in the melting point with increasing nanoclay content may be attributed to a decreasing structural regularity of LLDPE in the presence of nanofiller. It is obvious from Tables 4 and 5 that crystallinity decreases with crosslinking. For samples prepared by the BG process, addition of nanoclay did not change the crystallinity, while for samples prepared by the AG process, crystallinity decreased with increasing nanoclay content. This reduction may be attributed to an increase of gel content of the samples prepared by the AG process.

\section{Conclusions}

Silane-grafted LLDPE/layered silicate nanocomposites were prepared by melt mixing in an internal mixer followed by crosslinking in hot water. The grafting additives were a mixture of vinyl-trimethoxysilane and di-cumyl peroxide. Two methods, AG and BG, were used based on the sequence of adding the grafting agents and the nanoclay into the polyethylene melt. Grafting was confirmed by FTIR analysis. A partially exfoliated morphology of the nanoclay was observed by WAXS measurements. The gel content of samples prepared by adding the nanoclay into grafted-LLDPE (process route AG) was higher than the gel content of samples prepared by adding the nanoclay before the grafting reaction (process route $\mathrm{BG}$ ). The rate of crosslinking increased with increase of nanoclay content because of the high polarity of the nanofiller and the resulting increase in the absorption of water molecules. Tensile strength of silane grafted samples increased with the addition of nanoclay slightly, while elongation at break decreased dramatically for samples produced by the AG process. The melting behaviour of polyethylene is considerably affected by crosslinking. For samples prepared

Table 4. Melting point $\left(T_{m}\right)$, crystallization point $\left(T_{c}\right)$ and crystallinity percent for different samples prepared BG process

\begin{tabular}{|l|c|c|c|c|c|}
\hline \multicolumn{1}{|c|}{ MMT content } & LLDPE & XLLDPE & XLLDPE-1 phr MMT & XLLDPE-2 phr MMT & XLLDPE-3 phr MMT \\
\hline$T_{m}\left[{ }^{\circ} \mathrm{C}\right]$ & 122.71 & 121.19 & 121.80 & 123.72 & 121.82 \\
\hline${ }^{\mathrm{a}} T_{c}\left[{ }^{\circ} \mathrm{C}\right]$ & 108.24 & 108.45 & 107.49 & 101.20 & 107.26 \\
\hline$\Delta H_{m}[\mathrm{~J} / \mathrm{g}]$ & 100.40 & 91.28 & 94.13 & 92.21 & 92.00 \\
\hline$\Delta H_{c}[\mathrm{~J} / \mathrm{g}]$ & -89.57 & -79.84 & -83.63 & -80.05 & -80.71 \\
\hline Percent crystallinity [\%] & 34 & 31 & 32 & 31 & 31 \\
\hline
\end{tabular}

${ }^{\text {afor }} T_{c}$ only the values for strong peak have been presented

Table 5. Melting point $\left(T_{m}\right)$, crystallization point $\left(T_{c}\right)$ and crystallinity percent for different samples prepared AG process

\begin{tabular}{|l|c|c|c|c|c|}
\hline \multicolumn{1}{|c|}{ MMT content } & LLDPE & XLLDPE & XLLDPE-1 phr MMT & XLLDPE-2 phr MMT & XLLDPE-3 phr MMT \\
\hline$T_{m}\left[{ }^{\circ} \mathrm{C}\right]$ & 122.71 & 121.19 & 122.53 & 117.25 & 116.50 \\
\hline${ }^{\mathrm{a}} T_{c}\left[{ }^{\circ} \mathrm{C}\right]$ & 108.24 & 108.45 & 108.26 & 99.38 & 98.96 \\
\hline$\Delta H_{m}[\mathrm{~J} / \mathrm{g}]$ & 100.40 & 91.28 & 90.80 & 87.32 & 86.09 \\
\hline$\Delta H_{c}[\mathrm{~J} / \mathrm{g}]$ & -89.57 & -79.84 & -80.33 & -80.55 & -76.63 \\
\hline Percent crystallinity [\%] & 34 & 31 & 30 & 29 & 29 \\
\hline
\end{tabular}

${ }^{\text {afor }} T_{c}$ only the values for strong peak have been presented 
by the AG process, the melting point shifted to lower temperatures with increasing nanoclay content, and a deceasing crystallinity was observed.

\section{References}

[1] Rado R., Zelenak P.: Crosslinking of polyethylene. International Polymer Science and Technology, 19, 33-47 (1992).

[2] Thorburn B.: Crosslinking techniques for electrical jacketing materials. in 'Proceedings of ANTEC 94' Conference San Francisco, USA' 1379-1385 (1994).

[3] Roberts B. E., Verne S.: Industrial applications of different methods of crosslinking polyethylene. Plastic and Rubber Processing and Applications, 4, 135-139 (1984).

[4] Billet C., Delfosse L.: The combustion of polyolefins filled with metallic hydroxides and antimony trioxide. Polymer Degradation and Stability, 30, 89-99 (1990). DOI: 10.1016/0141-3910(90)90119-R

[5] Veselý K, Ruchlý J., Kummer M., Jancar J.: Flammability of highly filled polyolefins. Polymer Degradation and Stability, 30, 101-110 (1990). DOI: $\underline{10.1016 / 0141-3910(90) 90120-\mathrm{V}}$

[6] Hippi U., Mattila J., Korhonen M., Seppälä J.: Compatibilization of polyethylene/aluminum hydroxide (PE/ATH) and polyethylene/magnesium hydroxide (PE/MH) composites with functionalized polyethylenes. Polymer, 44, 1193-1201 (2003). DOI: $\underline{10.1016 / \mathrm{S} 0032-3861(02) 00856-X}$

[7] Anthonietta G., Shanks R. A.: Structural and thermal interpretation of the synergy and interaction between the fire retardant magnesium hydroxide and zinc borate. Polymer Degradation and Stability, 92, 2-13 (2007).

DOI: $10.1016 /$ j.polymdegradstab.2006.10.006

[8] Yeh J. T., Yang H. M., Huang S. S.: Combustion of polyethylene filled with metallic hydroxide and crosslinkable polyethylene. Polymer Degradation and Stability, 50, 229-234 (1995). DOI: $10.1016 / 0141-3910(95) 00171-9$

[9] Wang Z., Hu Y., Gui Z., Zong R.: Halogen-free flame retardation and silane crosslinking of polyethylenes. Polymer Testing, 22, 533-538 (2003). DOI: $\underline{10.1016 / \mathrm{S} 0142-9418(02) 00149-6}$

[10] Azizi H., Barzin J., Morshedian J.: Silane crosslinking of polyethylene: The effects of EVA, ATH and $\mathrm{Sb}_{2} \mathrm{O}_{3}$ on properties of the production in continuous grafting of LDPE. Express Polymer Letters, 1, 378-384 (2007).

DOI: $10.3144 /$ expresspolymlett.2007.53

[11] Patel H. A., Somani R. S., Bajaj H. C., Jasra R. V.: Nanoclays for polymer nanocomposites, paints, inks, greases and cosmetics formulations, drug delivery vehicle and waste water treatment. Bulletin of Materials Science, 29, 133-145 (2006).

DOI: $\underline{10.1007 / \mathrm{BF} 02704606}$
[12] Vaia R.: Polymer nanocomposites open a new dimensions for plastics and composites. AMPTIAC Q, 6, 17-24 (2002).

[13] Hussain F., Hojjati M., Okamoto R., Gorga R. E.: Polymer-matrix nanocomposites, processing, manufacturing and applications: An overview. Journal of Composite Materials, 40, 1511-1575 (2006). DOI: $\underline{10.1177 / 0021998306067321}$

[14] Bhat G., Hedge R. R., Kamath M. G., Deshpande B.: Nanoclay reinforced fibers and nonwovens. Journal of Engineered Fibers and Fabrics, 3, 22-34 (2008).

[15] Jiang L-Y., Wei K-H.: Bulk and surface properties of layered silicate/fluorinated polyimide nanocomposites. Journal of Applied Physics, 92, 6219-6223 (2002).

DOI: $\underline{10.1063 / 1.1516268}$

[16] Wang S., Hu Y., Qu Z., Wang Z., Chen Z., Fan W.: Preparation and flammability properties of polyethylene/clay nanocomposites by melt intercalation method from $\mathrm{Na}^{+}$montmorillonite. Materials Letters, 57, 2675-2678 (2003).

DOI: 10.1016/S0167-577X(02)01354-X

[17] Zhang J., Wilkie C.: Preparation and flammability properties of polyethylene-clay nanocomposites. Polymer Degradation and Stability, 80, 163-169 (2003).

DOI: $10.1016 / \mathrm{S} 0141-3910(02) 00398-1$

[18] Heinemann J., Richert P., Thomann R., Mülhaupt R.: Polyolefin nanocomposites formed by melt compounding and transition metal catalyzed ethene homoand copolymerization in the presence of layered silicates. Macromolecular Rapid Communications, 20, 423-430 (1999).

DOI: $10.1002 /($ SICI)1521-3927(19990801)20:8<423: AID-MARC423>3.0.CO;2-N

[19] Alexandre M., Dubois P., Sun T., Graces J. M., Jérome R.: Polyethylene-layered silicate nanocomposites prepared by the polymerization-filling technique: Synthesis and mechanical properties. Polymer, 43, 2123-2132 (2002). DOI: $\underline{10.1016 / \mathrm{S} 0032-3861(02) 00036-8}$

[20] Song L., Hu Y., Wang S., Chen Z., Fan W.: Study on the solvothermal preparation of polyethylene/organophilic montmorillonite nanocomposites. Journal of Materials Chemistry, 12, 3152-3155 (2002). DOI: $10.1039 / \mathrm{b} 201488 \mathrm{~b}$

[21] Mehrabzadeh M., Kamal M.: Polymer-clay nanocomposites based on blends of polyamide- 6 and polyethylene. The Canadian Journal of Chemical Engineering, 80, 1083-1092 (2002). DOI: $\underline{10.1002 / \text { cjce } .5450800610}$

[22] Koo C. M., Kim S. O., Chung I. J.: Study on morphology evolution, orientatinal behaviour and anisotropic phase formation of highly-filled polymer layered silicate nanocomposites. Macromolecules, 36, 27482757 (2003). DOI: $\underline{10.1021 / \mathrm{ma} 021377 \mathrm{n}}$ 
[23] Koo C. M., Ham H. T., Kim S. O., Wang K. H., Chung I. J.: Morphology evolution and anisotropic phase formation of the maleated polyethylene-layered silicate nanocomposites. Macromolecules, 35, 5116-5122 (2002).

DOI: $\underline{10.1021 / \mathrm{ma} 011770 \mathrm{~d}}$

[24] Bafna A., Beaucage G., Mirabella F., Mehta S.: 3D hierarchical orientation in polymer-clay nanocomposite films. Polymer, 44, 1103-1115 (2003). DOI: $10.1016 / \mathrm{S} 0032-3861(02) 00833-9$

[25] Gopakumar T. G., Lee J. A., Kongtopoulou M., Parent J. S.: Influence of clay exfoliation on the physical properties of montmorillonite/polyethylene composite. Polymer, 43, 5483-5491 (2002). DOI: 10.1016/S0032-3861(02)00403-2

[26] Kaempfer D., Thomann R., Mülhaupt K.: Melt compounding of the syndiotactic polypropylene nanocomposites containing organophilic layered silicate and in-situ formed core/shell nanoparticles. Polymer, 43, 2909-2916 (2002).

DOI: $10.1016 / \mathrm{S} 0032-3861(02) 00113-1$

[27] Antochshuk V., Jaromiec M.: Functionalized mesoporous materials obtained via interfacial reactions in self-assembled silica surfactant systems. Chemistry of Materials, 12, 2496-2501 (2000). DOI: $10.1021 / \mathrm{cm} 000268 \mathrm{p}$

[28] Mercier L., Pinnavaia T. J.: Direct synthesis of hybrid organic-inorganic nanoporous silica by a neutral amine assembly route: Structure-function control by stoichiometric incorporation of organosiloxane molecules. Chemistry of Materials, 12, 188-196 (2000). DOI: $\underline{10.1021 / \mathrm{cm} 990532 \mathrm{i}}$
[29] Seçkin T., Gültek A., Içgduygu M. G., Önal Y.: Polymerization and characterization of acrylonitrile with $\gamma$-methacryloxypropyltrimethoxy-silane grafted bentonite clay. Journal of Applied Polymer Science, 84, 164-171 (2002).

DOI: $10.1002 /$ app.10289

[30] He H. P., Duchet J., Galy J., Gerard J-F.: Grafting of swelling clays with 3-aminopropyltriethoxysilane. Journal of Colloid and Interface Science, 288, 171176 (2002).

DOI: $10.1016 /$ j.jcis.2005.02.092

[31] Hatakeyana T., Zhenhai L.: Handbook of thermal analysis. Wiley, New York (1998).

[32] Mittal V.: Polymer layered silicate nanocomposites: A Review. Materials, 2, 992-1057 (2009). DOI: $10.3390 / \mathrm{ma} 2030992$

[33] Barus S., Zanetti M., Lazzari M., Costa L.: Preparation of polymeric hybrid nanocomposites base on PE and nanosilica. Polymer, 50, 2595-2600 (2009). DOI: 10.1016/j.polymer.2009.04.012

[34] Zuiderduin W. C. J., Westzaan C., Huétink J., Gaymans R. J.: Toughening of polypropylene with calcium carbonate particles. Polymer, 44, 261-275 (2003). DOI: $10.1016 / \mathrm{S} 0032-3861(02) 00769-3$

[35] Kuan H-C., Kuan J-F., Ma C-C. M., Huang J-M.: Structure characteristics and thermal properties of silane-grafted-polyethylene/clay nanocomposite prepared by reactive extrusion. Journal of Applied Polymer Science, 96, 2383-2391 (2005).

DOI: 10.1002/app.21694 